\title{
The Small-Signal Stability of Offshore Wind Power Transmission Inspired by Particle Swarm Optimization
}

\author{
Jiening Li, ${ }^{1}$ Hanqi Huang, ${ }^{1}$ Xiaoning Chen, ${ }^{2}$ Lingxi Peng $\mathbb{D},{ }^{1,3}$ Liang Wang $\mathbb{D}^{4},{ }^{4}$ \\ and Ping Luo $\left.{ }^{5}\right)^{5}$ \\ ${ }^{1}$ School of Mechanical and Electrical Engineering, Guangzhou University, Guangzhou 510006, China \\ ${ }^{2}$ School of Mathematics and Information Science, Guangzhou University, Guangzhou 510006, China \\ ${ }^{3}$ Data Recovery Key Laboratory of Sichuan Province, Neijiang Normal University, Sichuan 641100, China \\ ${ }^{4}$ School of Public Administration, Guangzhou University, Guangzhou 510006, China \\ ${ }^{5}$ School of Economics and Statistics, Guangzhou University, Guangzhou 510006, China
}

Correspondence should be addressed to Lingxi Peng; scu.peng@gmail.com, Liang Wang; wl_1998@gzhu.edu.cn, and Ping Luo; 514923134@qq.com

Received 6 May 2020; Accepted 22 May 2020; Published 15 July 2020

Academic Editor: Shuping He

Copyright (c) 2020 Jiening Li et al. This is an open access article distributed under the Creative Commons Attribution License, which permits unrestricted use, distribution, and reproduction in any medium, provided the original work is properly cited.

\begin{abstract}
Voltage source converter-high-voltage direct current (VSC-HVDC) is the mainstream technology of the offshore wind power transmission, which has been rapidly developed in recent years. The small-signal stability problem is closely related to offshore wind power grid-connected safety, but the present study is relatively small. This paper established a mathematical model of the doubly fed induction generator (DFIG) integrated into the IEEE9 system via VSC-HVDC in detail, and small-signal stability analysis of offshore wind farm (OWF) grid connection is specially studied under different positions and capacities. By selecting two load nodes and two generator nodes in the system for experiments, the optimal location and capacity of offshore wind power connection are obtained by comparing the four schemes. In order to improve the weak damping of the power system, this paper presents a method to determine the parameters of the power system stabilizer (PSS) based on the particle swarm optimization (PSO) algorithm combined with different inertia weight functions. The optimal position of the controller connected to the grid is obtained from the analysis of modal control theory. The results show that, after joining the PSS control, the system damping ratio significantly increases. Finally, the proposed measures are verified by MATLAB/Simulink simulation. The results show that the system oscillation can be significantly reduced by adding PSS, and the small-signal stability of offshore wind power grid connection can be improved.
\end{abstract}

\section{Introduction}

Offshore wind power, as a clean and sustainable technology, has been developed rapidly in recent years [1]. At present, the total installed capacity in Europe is increasing every year, among which the UK and Germany dominate the offshore wind power industry [2]. According to Wind Europe's High Scenario, it is estimated that the offshore wind energy capacity in Europe will reach 99 GW by 2030 [3]. Nowadays, the mainstream transmission technology is VSC-HVDC [4-6]. Compared to other traditional transmission modes, it has the advantages of independent control of the active and reactive power output, smaller power loss, and lower voltage drop [7-10].
Small-signal stability analysis is to study the dynamic response characteristics of the power system after small disturbances (including random fluctuations in power generation or consumption) and to evaluate their ability to suppress oscillations [11]. It is of great significance to promote the development of wind power and improve the safe stability of the system, which needs urgent attention [12]. However, there are few studies on the small-signal stability analysis of the offshore wind power grid connected by VSC-HVDC transmission at present. Based on the smallsignal stability problem of the offshore wind power system transmitted by VSC-HVDC, the damping control of the system is increased by introducing PID regulation at the converter station. The modeling method does not consider 
the aerodynamic model, and the selection of PID parameters based on eigenvalues has limitations [13]. Small-signal stability analysis method from the perspective of voltage and frequency is discussed in $[14,15]$. In [14], the variability of wind power was considered as the interference source of the system and used Prony analysis and swing-based frequency response metric to study the influence of the small signal on the large offshore wind power system. However, the whole system modeling process has not been described in detail but is focused on analysis. In [15], the model of the offshore AC network for point-to-point VSC-HVDC transmission is deduced in detail, and the droop gain boundary under the stable operation is determined by eigenvalue analysis. A lowpass filter was introduced to improve the system damping, but the effect of different grid-connected positions and capacity on the small signal of the system was not considered. At present, neural networks [16,17], deep learning, and machine learning methods have been widely used in various fields, and remarkable results have been achieved [18, 19].

To improve the stability of the system under the small signal and large signal, the PSO algorithm is used to optimize the parameters of the DFIG controller. However, the PSO algorithm will fall into local optimum, and more controller equations increase the dimension of the state matrix, which will slow down the fast operation of the system [20]. In these studies, although scholars have studied the small-signal stability of offshore wind power grid connection in different fields, it is still in the exploratory stage to change the gridconnected position and capacity of offshore wind farms for small-signal stability analysis and to apply damping control.

Aiming at the problem of small-signal stability of the offshore wind power grid-connected system, this paper firstly establishes a complete VSC-HVDC transmission offshore wind power grid-connected mathematical model and then analyzes the impact of OWFs on the small-signal stability of the system under different positions and capacities. Secondly, PSS is introduced for damping control. The optimal position of the PSS connected to the power grid is determined by modal control theory, and the parameters of the controller are determined by the PSO algorithm combined with different inertia weight functions. Finally, the correctness of the established model and the effectiveness of the proposed control measures are verified by MATLAB/ Simulink simulation.

\section{Modeling of Offshore Wind Power Transmitted by VSC-HVDC}

This paper uses the typical offshore wind power grid connection system [21] for reference, and the designed system topology is shown in Figure 1. The OWFs are composed of 10 2-MW DFIGs, and they are equivalent to a DFIG representation according to the aggregated model [22]. The wind turbine (WT) runs on the low-speed (LS) shaft, the generator runs on the high-speed (HS) shaft, and the gearbox connects the two to act as the booster. Each $690 \mathrm{~V}$ DFIG is connected to $10 \mathrm{kV}$ bus through the boost transformer $X_{\mathrm{T} 0}$ and then sent to $110 \mathrm{kV}$ bus through the boost transformer $X_{\mathrm{T} 1}$ and the transmission line $X_{\mathrm{T} 1}$. VSC1 and
VSC2 are converter stations, which play the roles of the rectifier and the inverter, respectively. The HVDC plays the role of power transmission. In addition, there are resistancecapacitance (RC) filters and phase reactors, whose influence on the system is ignored in this paper. The VSC-HVDC outlet $u_{\mathrm{s} 2}$ is connected to the $230 \mathrm{kV} 3$-machine, 9-bus test system [23] via the boost transformer $X_{\mathrm{T} 2}$ and the transmission line $X_{\mathrm{L} 2}$, which is represented by IEEE9.

2.1. Aerodynamic Model. WT is driven by the wind, which is converted into mechanical energy through three blades. The equations of the aerodynamic model [24] are given by

$$
\begin{aligned}
C_{\mathrm{P}} & =0.22\left(\frac{116}{\lambda_{i}}-0.4 \beta-5\right) e^{-12.5 / \lambda_{i}}, \\
\frac{1}{\lambda_{i}} & =\frac{1}{\lambda+0.08 \beta^{2}}-\frac{0.035}{\beta^{3}+1}, \\
T_{\mathrm{t}} & =\frac{P_{\mathrm{t}}}{\omega_{\mathrm{t}}}=\frac{\rho \pi r^{2} C_{\mathrm{P}} v^{3}}{2 \omega_{\mathrm{t}}},
\end{aligned}
$$

where $C_{\mathrm{p}}$ is the coefficient of wind energy utilization; $\beta$ is the pitch angle; $\lambda$ is the tip speed ratio $\left(\lambda=\omega_{t} r / \nu\right) ; \omega_{t}$ is the mechanical angular velocity of the WT; $r$ is the radius of the wind wheel; $v$ is the wind speed; $P_{\mathrm{t}}$ is the mechanical power output by the WT; $T_{\mathrm{t}}$ is the mechanical torque; and $\rho$ is the air density.

2.2. Shafting Model. In order to ensure the accuracy of calculation, this paper selects the two-mass block shafting model. The mathematical model of the shafting model [25] is as follows:

$$
\left\{\begin{array}{l}
2 H_{\mathrm{t}} \frac{\mathrm{d} \omega_{\mathrm{t}}}{\mathrm{d} t}=T_{\mathrm{t}}-K \theta-D\left(\omega_{\mathrm{t}}-(1-s) \omega_{\mathrm{s}}\right), \\
\frac{\mathrm{d} \theta}{\mathrm{d} t}=\omega_{\mathrm{b}}\left(\omega_{\mathrm{t}}-(1-s) \omega_{\mathrm{s}}\right) \\
-2 H_{\mathrm{g}} \omega_{\mathrm{s}} \frac{\mathrm{d} s}{\mathrm{~d} t}=K \theta+D\left(\omega_{\mathrm{t}}-(1-s) \omega_{\mathrm{s}}\right)-T_{\mathrm{e}}
\end{array}\right.
$$

where $H_{\mathrm{t}}$ and $H_{\mathrm{g}}$ are the inherent inertial time constants of the WT and the generator; $T_{\mathrm{t}}$ and $T_{\mathrm{e}}$ are the mechanical torque of the WT and the electromagnetic torque of the generator; $K$ and $D$ are the stiffness and damping coefficients of the shaft; $\theta$ is the shaft torsional angle; $\omega_{\mathrm{t}}$ and $\omega_{\mathrm{r}}$ are the speeds of the rotor of the WT and the generator; $\omega_{\mathrm{s}}$ is the stator speed of the generator; and $\omega_{\mathrm{b}}$ is the base value of rotational speed.

2.3. Pitch Angle Control Model. To ensure the smooth power output of the OWFs, the pitch angle [26] needs to be controlled. The equations are given by

$$
\left\{\begin{array}{l}
\frac{\mathrm{d} \beta}{\mathrm{d} t}=\frac{1}{T_{\beta}}\left(\beta_{\text {ref }}-\beta\right), \\
\beta_{\text {ref }}=K_{\mathrm{p} 0} \frac{\mathrm{d} \omega_{t}}{\mathrm{~d} t}+K_{10} \Delta \omega_{\mathrm{t}},
\end{array}\right.
$$




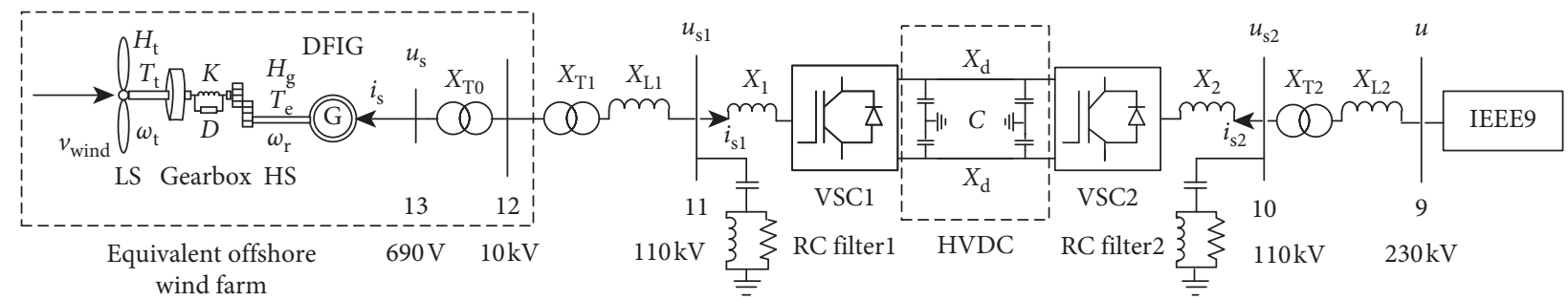

FIgURE 1: The topology of the whole system.

where $T_{\beta}$ is the inertial time constant of the pitch angle control model; $\beta_{\text {ref }}$ and $\omega_{t_{-} \text {ref }}$ are the reference values of the pitch angle and the WT speed; and $K_{\mathrm{p} 0}$ and $K_{\mathrm{I} 0}$ are the proportional and integral coefficients of the controller.

2.4. DFIG Model. Currently, DFIG is the most widely used WT. Ignoring the electromagnetic transient process of stator winding, the mathematical model of the DFIG [27] is as follows:

$$
\left\{\begin{array}{l}
\frac{\mathrm{d} e_{\mathrm{d}}^{\prime}}{\mathrm{d} t}=-\frac{1}{T_{0}^{\prime}} e_{\mathrm{d}}^{\prime}+s \omega_{\mathrm{s}} e_{\mathrm{q}}^{\prime}-\frac{\left(X_{\mathrm{s}}-X_{\mathrm{s}}^{\prime}\right)}{T_{0}^{\prime}} i_{\mathrm{qs}}-\frac{\omega_{\mathrm{s}} L_{\mathrm{m}}}{L_{\mathrm{rr}}} u_{\mathrm{qr}}, \\
\frac{\mathrm{d} e_{\mathrm{q}}^{\prime}}{\mathrm{d} t}-s \omega_{\mathrm{s}} e_{\mathrm{d}}^{\prime}-\frac{1}{T_{0}^{\prime}} e_{\mathrm{q}}^{\prime}+\frac{\left(X_{\mathrm{s}}-X_{\mathrm{s}}^{\prime}\right)}{T_{0}^{\prime}} i_{\mathrm{ds}}+\frac{\omega_{\mathrm{s}} L_{\mathrm{m}}}{L_{\mathrm{rr}}} u_{\mathrm{dr}}, \\
u_{\mathrm{dr}}=R_{\mathrm{r}} i_{\mathrm{dr}}+T_{\mathrm{b}}^{\prime} \frac{\mathrm{d} i_{\mathrm{dr}}}{\mathrm{d} t}-s \omega_{\mathrm{s}} T_{\mathrm{b}}^{\prime} i_{\mathrm{qr}}, \\
u_{\mathrm{qr}}=R_{\mathrm{r}} i_{\mathrm{qr}}+T_{\mathrm{b}}^{\prime} \frac{\mathrm{d} i_{\mathrm{qr}}}{\mathrm{d} t}+s \omega_{\mathrm{s}}\left(T_{\mathrm{a}}^{\prime} u_{\mathrm{qs}}+T_{\mathrm{b}}^{\prime} i_{\mathrm{dr}}\right) \\
i_{\mathrm{ds}}=\frac{1}{L_{\mathrm{ss}}} u_{\mathrm{qs}}-\frac{L_{\mathrm{m}}}{L_{\mathrm{ss}}} i_{\mathrm{dr}}, \\
i_{\mathrm{qs}}=-\frac{L_{\mathrm{m}}}{L_{\mathrm{ss}}} i_{\mathrm{qr}},
\end{array}\right.
$$

where $T_{0}^{\prime}=L_{\mathrm{rr}} / R_{\mathrm{r}} ; T_{a}^{\prime}=L_{\mathrm{m}} / L_{\mathrm{ss}} ; T_{b}^{\prime}=L_{\mathrm{rr}}-L_{\mathrm{m}} / L_{\mathrm{ss}} ; X_{\mathrm{s}}=\omega_{\mathrm{s}} L_{\mathrm{ss}}$; $L_{\mathrm{ss}}=L_{\mathrm{s}}+L_{\mathrm{m}}$; and $L_{\mathrm{rr}}=L_{\mathrm{r}}+L_{\mathrm{m}}$ are the sum of self-inductance of the stator and the rotor; $R_{\mathrm{s}}$ and $R_{\mathrm{r}}$ are the resistances of the stator and the rotor; $L_{\mathrm{m}}$ is the mutual inductance between the stator and the rotor; $X_{\mathrm{s}}$ is the reactance of the stator; $e_{\mathrm{d}}^{\prime}=-\left(\omega_{\mathrm{s}} L_{\mathrm{m}} / L_{\mathrm{rr}}\right) \psi_{\mathrm{qr}} ; \quad e_{\mathrm{q}}^{\prime}=\left(\omega_{\mathrm{s}} L_{\mathrm{m}} / L_{\mathrm{rr}}\right) \psi_{\mathrm{dr} r} ; \quad X_{\mathrm{s}}^{\prime}=\omega_{\mathrm{s}} / L_{\mathrm{rr}}$ $\left(L_{\mathrm{ss}} L_{\mathrm{rr}}-L_{\mathrm{m}}\right) ; e_{\mathrm{d}}^{\prime}$ and $e_{\mathrm{q}}^{\prime}$ are the $d$ - and $q$-axis components of the transient voltages; $X_{s}^{\prime}$ is the transient resistance of the stator; and $\psi_{\mathrm{dr}}$ and $\psi_{\mathrm{qr}}$ are the $d$ - and $q$-axis components of the rotor flux, respectively. $i_{\mathrm{ds}}, i_{\mathrm{qs}}, i_{\mathrm{dr}}$, and $i_{\mathrm{qr}}$ are the $d$ - and $q$ axis components of the stator and rotor currents, respectively. Let the stator flux $\psi_{\mathrm{s}}$ always reunite with the $d$-axis; then, $u_{\mathrm{ds}}=0$ and $u_{\mathrm{qs}}=\psi_{\mathrm{s}} \cdot u_{\mathrm{ds}}, u_{\mathrm{qs}}, u_{\mathrm{dr}}$, and $u_{\mathrm{qr}}$ are the voltages of the stator and the rotor.

The active and the reactive power output of OWFs are

$$
\left\{\begin{array}{l}
P_{\mathrm{e}}=\frac{3}{2}\left[\frac{R_{\mathrm{r}}\left(P_{\mathrm{s}}^{2}+Q_{\mathrm{s}}^{2}\right)}{T_{\mathrm{a}}^{\prime 2} u_{\mathrm{s}}^{2}}+\frac{2 R_{\mathrm{r}} Q_{\mathrm{s}}}{T_{\mathrm{a}}^{\prime 2} L_{\mathrm{ss}}}+(1-s \omega) P_{\mathrm{s}}+\frac{R_{\mathrm{r}} u_{\mathrm{s}}^{2}}{L_{\mathrm{m}}^{2}}\right], \\
Q_{\mathrm{e}}=\frac{3}{2}\left[-s \omega T_{\mathrm{b}}^{\prime}\left(\frac{P_{\mathrm{s}}^{2}+Q_{\mathrm{s}}^{2}}{T_{\mathrm{a}}^{\prime 2} u_{\mathrm{s}}^{2}}+\frac{2 Q_{\mathrm{s}}}{T_{\mathrm{a}}^{\prime 2} L_{\mathrm{ss}}}+\frac{u_{\mathrm{s}}^{2}}{L_{\mathrm{m}}^{2}}\right)+\left(1-s \omega_{\mathrm{s}}\right) Q_{\mathrm{s}}-\frac{s \omega_{\mathrm{s}} u_{\mathrm{s}}^{2}}{L_{\mathrm{ss}}}\right] .
\end{array}\right.
$$

2.5. VSC-HVDC Model. According to the relationship between the three-phase stationary coordinate system and the $d$ and $q$ synchronous rotating coordinate system, after the Park transformation, the 7-order mathematical model $[13,21]$ can be obtained as follows:

$$
\left\{\begin{array}{l}
L_{1} \frac{\mathrm{d} i_{1 \mathrm{~d}}}{\mathrm{~d} t}=-R_{1} i_{1 \mathrm{~d}}-\omega_{1} L_{1} i_{1 \mathrm{q}}+u_{\mathrm{s} \mathrm{d} 1}-K_{1} u_{\mathrm{d} 1} \cos \delta_{1}, \\
L_{1} \frac{\mathrm{d} i_{1 \mathrm{q}}}{\mathrm{d} t}=-R_{1} i_{1 \mathrm{q}}+\omega_{1} L_{1} i_{1 \mathrm{~d}}+u_{\mathrm{sq} 1}-K_{1} u_{\mathrm{d} 1} \sin \delta_{1}, \\
L_{2} \frac{\mathrm{d} i_{2 \mathrm{~d}}}{\mathrm{~d} t}=-R_{2} i_{2 \mathrm{~d}}-\omega_{2} L_{2} i_{2 \mathrm{q}}+u_{\mathrm{s} \mathrm{d} 2}-K_{2} u_{\mathrm{d} 2} \cos \delta_{2}, \\
L_{2} \frac{\mathrm{d} i_{2 \mathrm{~d}}}{\mathrm{~d} t}=-R_{2} i_{2 \mathrm{q}}-\omega_{2} L_{2} i_{2 \mathrm{~d}}+u_{\mathrm{sq} 2}-K_{2} u_{\mathrm{d} 2} \sin \delta_{2}, \\
C \frac{\mathrm{d} u_{\mathrm{d} 1}}{\mathrm{~d} t}=\frac{3 K_{1}}{2}\left(i_{1 \mathrm{~d}} \cos \delta_{1}+i_{1 \mathrm{q}} \sin \delta_{1}\right)-i_{\mathrm{d}}, \\
C \frac{\mathrm{d} u_{\mathrm{d} 2}}{\mathrm{~d} t}=\frac{3 K_{2}}{2}\left(i_{2 \mathrm{q}} \cos \delta_{2}+i_{2 \mathrm{q}} \sin \delta_{2}\right)-i_{\mathrm{d}}, \\
L_{\mathrm{d}} \frac{\mathrm{d} i}{\mathrm{~d} t}=u_{\mathrm{d} 1}-u_{\mathrm{d} 2}-R_{\mathrm{d}} i_{\mathrm{d}},
\end{array}\right.
$$

where the physical quantities corresponding to the rectifier and the inverter station are denoted by subscripts " 1 " and "2," respectively. $i_{1 \mathrm{~d}}, i_{1 \mathrm{q}}, i_{2 \mathrm{~d}}$, and $i_{2 \mathrm{q}}$ represent the current components of the AC network; $u_{\mathrm{sd} 1}, u_{\mathrm{sq} 1}, u_{\mathrm{sd}}$, and $u_{\mathrm{sq} 2}$ represent the voltage components of the AC network; $u_{\mathrm{d} 1}$, $u_{\mathrm{q} 1}, u_{\mathrm{d} 2}$, and $u_{\mathrm{q} 2}$ represent the voltage components between buses of the DC system; and $K_{1}$ and $K_{2}$ are the voltage utilization coefficients of the DC system. $\delta_{1}$ and $\delta_{2}$ are the deviation angles between the voltage of the converter station 
and the bus voltage of the AC system; $\omega_{1}$ and $\omega_{2}$ are the fundamental angular frequencies of the AC system. $i_{\mathrm{d}}$ is the DC current transmitted by the high-voltage transmission line.

2.6. System Interface Model. Position the stator voltage $u_{\mathrm{s}}$ on the $d$-axis, and the voltage vector between the DFIG and the rectifier station is shown in Figure 2.

Its mathematical relationship is

$$
\left[\begin{array}{c}
u_{\mathrm{sd} 1} \\
u_{\mathrm{sq} 1}
\end{array}\right]=\left[\begin{array}{c}
u_{\mathrm{ds}} \\
u_{\mathrm{qs}}
\end{array}\right]+\left[\begin{array}{cc}
0 & -X_{\mathrm{TL} 1} \\
X_{\mathrm{TL} 1} & 0
\end{array}\right]\left[\begin{array}{c}
i_{\mathrm{ds}} \\
i_{\mathrm{qs}}
\end{array}\right],
$$

where $X_{\mathrm{TL} 1}$ is the total impedance of line 1; $X_{\mathrm{T} 0}$ is the equivalent transformer impedance of OWFs; and $X_{\mathrm{T} 1}$ and $X_{\mathrm{L} 1}$ are the transformer and the circuit impedance of line 1.

Position the terminal voltage $u$ of the power system on the $x$-axis, and the vector between the inverter station and the power system is shown in Figure 3.

Its mathematical relationship is

$$
\left[\begin{array}{c}
u_{\mathrm{sd} 2} \\
u_{\mathrm{sq} 2}
\end{array}\right]=\left[\begin{array}{c}
\cos \varphi \\
-\sin \varphi
\end{array}\right] u-\left[\begin{array}{cc}
0 & -X_{\mathrm{TL} 2} \\
X_{\mathrm{TL} 2} & 0
\end{array}\right]\left[\begin{array}{l}
i_{2 \mathrm{~d}} \\
i_{2 \mathrm{q}}
\end{array}\right] .
$$

2.7. Complete Model. All the equations of DFIG and VSCHVDC are combined and linearized near the stable value:

$$
\left[\begin{array}{c}
\frac{\mathrm{d} \Delta x_{10}}{\mathrm{~d} t} \\
0
\end{array}\right]=\left[\begin{array}{cc}
\widetilde{A} & \widetilde{B} \\
\widetilde{C} & \widetilde{D}
\end{array}\right]\left[\begin{array}{c}
\Delta x_{10} \\
\Delta y_{10}
\end{array}\right],
$$

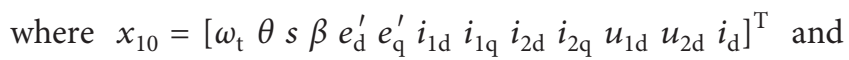
$y_{10}=\left[\begin{array}{ll}i_{\mathrm{ds}} & i_{\mathrm{qs}}\end{array}\right]^{\mathrm{T}}$.

The offshore wind power transmitted by VSC-HVDC is integrated into the IEEE9 system, as shown in Figure 4. The small-signal equation of the system is

$$
\frac{\mathrm{d} \Delta x}{\mathrm{~d} t}=A \Delta x,
$$

where $\quad x=\left[\begin{array}{llll}x_{1} & x_{2} & x_{3} & x_{10}\end{array}\right]^{\mathrm{T}} ; \quad x_{1}=\left[\begin{array}{ll}\delta_{1} & \omega_{1}\end{array}\right]^{\mathrm{T}} ; \quad x_{2}=$ $\left[\begin{array}{lllllll}\delta_{2} & \omega_{2} & e_{\mathrm{q} 2}^{\prime} & e_{\mathrm{d} 2}^{\prime} & e_{\mathrm{fq} 2} & v_{\mathrm{R} 2} & v_{\mathrm{M} 2}\end{array}\right]^{\mathrm{T}} ; \quad$ and $\quad x_{3}=$ $\left[\begin{array}{lllllll}\delta_{3} & \omega_{3} & e_{\mathrm{q} 3}^{\prime} & e_{\mathrm{d} 3}^{\prime} & e_{\mathrm{fq} 3} & v_{\mathrm{R} 3} & v_{\mathrm{M} 3}\end{array}\right]^{\mathrm{T}}$.

After deducing the complete small-signal stability model of offshore wind power transmitted by VSC-HVDC, it is necessary to do further research on the influence of smallsignal stability on the system of offshore wind power in different positions and capacities.

\section{Small-Signal Stability Analyses}

This section will combine with the concrete example of the offshore wind power grid-connected position and capacity for small-signal stability analysis. Firstly, the parameters of each subsystem are initialized, which are detailed in

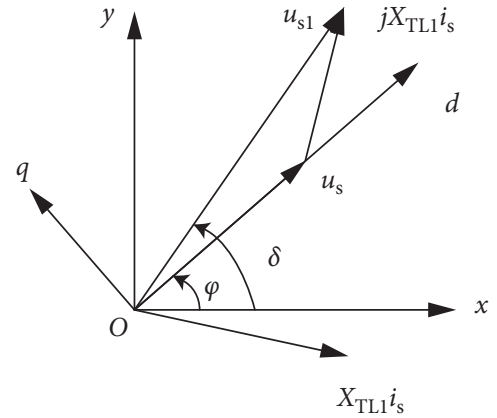

FIGURE 2: The voltage vector between the DFIG and the rectifier station.

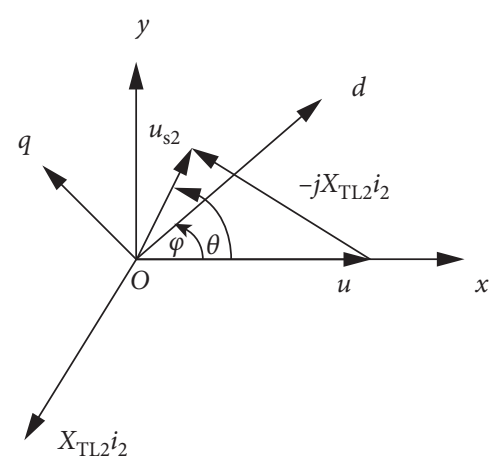

FIgURE 3: The voltage vector between the inverter station and the power system.

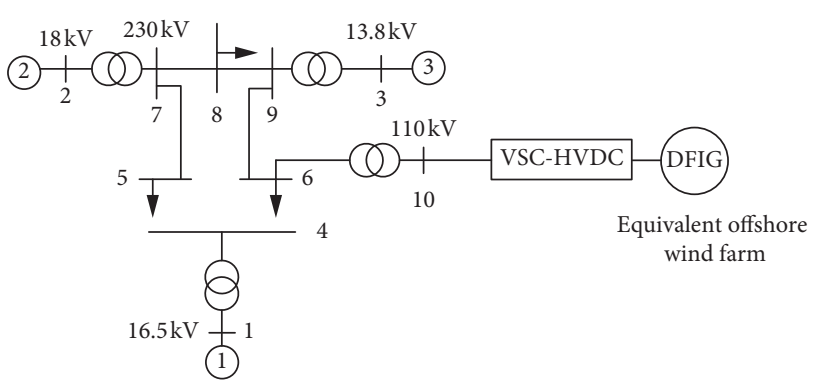

FIGURE 4: Schematic diagram of the equivalent offshore wind farm connected to the IEEE9 system by VSC-HVDC.

Appendix and then the state of OWFs is found before incorporation into the system. Finally, two load nodes and two generator nodes are chosen, and the influence of the offshore wind power grid connection is analyzed in detail.

3.1. Eigenvalue Analysis. When the OWFs are added at node 6 and the active power output is $0.5 \mathrm{pu}$, the eigenvalues of the system are shown in Table 1. It can be seen from Table 1 that the real part of the eigenvalues is all negative, which are on the left side of the imaginary axis, indicating that the original power system is running in a stable state.

$\lambda_{7,8}, \lambda_{10,11}, \lambda_{12,13}$, and $\lambda_{16,17}$ are related to the generator rotational speed $\left(\Delta \omega_{1}, \Delta \omega_{2}\right.$, and $\left.\Delta \omega_{3}\right)$ and the rotational speed difference $\Delta s$ of wind generator 10 , respectively, belonging to the electromechanical oscillation mode. 
TABLE 1: Eigenvalues of the system during stable state.

\begin{tabular}{lccc}
\hline Number & Eigenvalue & Number & Eigenvalue \\
\hline$\lambda_{1}$ & -99.9360 & $\lambda_{2}$ & -74.4198 \\
$\lambda_{3}$ & -52.7251 & $\lambda_{4}$ & -51.3813 \\
$\lambda_{5}$ & -31.1510 & $\lambda_{6}$ & -28.8327 \\
$\lambda_{7,8}$ & $-2.6655 \pm 18.2668 i$ & $\lambda_{9}$ & -12.9409 \\
$\lambda_{10,11}$ & $-0.6959 \pm 12.8937 i$ & $\lambda_{12,13}$ & $-0.1431 \pm 8.6461 i$ \\
$\lambda_{14,15}$ & $-4.7160 \pm 8.0754 i$ & $\lambda_{16,17}$ & $-0.1222 \pm 4.0611 i$ \\
$\lambda_{18,19}$ & $-4.4655 \pm 3.1380 i$ & $\lambda_{20,21}$ & -5.4943 \\
$\lambda_{21}$ & -4.1027 & $\lambda_{22}$ & -0.4476 \\
$\lambda_{23,24}$ & $-0.8287 \pm 0.9010 i$ & $\lambda_{25,26}$ & $-0.3560 \pm 0.5849 i$ \\
$\lambda_{27}$ & -0.0290 & $\lambda_{28,29}$ & $-0.0291 \pm 0.0502 i$ \\
\hline
\end{tabular}

3.2. Damping Ratio Analysis. Damping ratio [28] can reflect the speed and the characteristics of oscillation attenuation. The expression is given by

$$
\zeta=-\frac{\sigma}{\sqrt{\sigma^{2}+\omega^{2}}}
$$

where $\sigma$ and $\omega$ are the real and the imaginary part of the eigenvalue, respectively.

In the actual power system, it is generally required that the damping ratio of the electromechanical oscillation mode should be above 0.05 , and then the operating state of the system could be accepted. However, this principle is not unchanged. If the mode of fluctuation is not large when the system operation mode changes, it is acceptable to have such a low damping ratio (for example, 0.03) [28].

By changing different active power outputs and gridconnected positions of OWFs, the damping ratio curve in various cases can be obtained as shown in Figure 5.

\section{Control Measures}

In order to improve the weak damping instability of the system, it is necessary to add a controller to the system for auxiliary regulation. Firstly, PSS needs to be modeled, and the speed difference is used as the feedback signal to be added to the system voltage equation. Secondly, the optimal position of the PSS is determined by the detailed analysis of modal control theory.

Finally, the PSO algorithm is introduced, and the objective function is established according to the research content of this paper. The parameters of PSS controllers are determined with different inertia weight functions.

4.1. PSS Model. The main function of the PSS is to increase damping or suppress low-frequency oscillation of the power system [29]. The mathematical expression of the PSS is

$$
\left\{\begin{array}{l}
\frac{\mathrm{d} \Delta V_{1}}{\mathrm{~d} t}=\frac{K_{\text {gain }}}{T_{6}} \Delta \omega-\frac{1}{T_{6}} \Delta V_{1}, \\
\frac{\mathrm{d} \Delta V_{2}}{\mathrm{~d} t}=\frac{K_{\text {gain }}}{T_{6}} \Delta \omega-\frac{1}{T_{6}} \Delta V_{1}-\frac{1}{T_{5}} \Delta V_{2}, \\
\frac{\mathrm{d} \Delta V_{3}}{\mathrm{~d} t}=\frac{K_{\text {gain }} T_{1}}{T_{2} T_{6}} \Delta \omega-\frac{T_{1}}{T_{2} T_{6}} \Delta V_{1}-\frac{T_{1}-T_{5}}{T_{2} T_{5}} \Delta V_{2}-\Delta V_{3}, \\
\frac{\mathrm{d} \Delta V_{\mathrm{S}}}{\mathrm{d} t}=\frac{K_{\text {gain }} T_{1} T_{3}}{T_{2} T_{4} T_{6}} \Delta \omega-\frac{T_{1} T_{3}}{T_{2} T_{4} T_{6}} \Delta V_{1}-\frac{T_{3}\left(T_{1}-T_{5}\right)}{T_{2} T_{4} T_{5}} \Delta V_{2}-\frac{T_{3}-T_{2}}{T_{2} T_{4}} \Delta V_{3}-\frac{1}{T_{4}} \Delta V_{\mathrm{S}}
\end{array}\right.
$$

where the generator speed difference $V_{\mathrm{IS}}=\omega-\omega_{\mathrm{t}}$ is selected as the input signal. $V_{\mathrm{S}}$ is the output signal, which serves as the auxiliary input signal of the stator voltage equation $\Delta u_{\mathrm{qi}}$ $(i=1,2,3)$ of the IEEE9 system. $K_{\text {gain }}$ is the gain of the amplification link; $T_{6}$ is the time constant of the measurement link. $T_{5}$ is the time constant of the filtering link. $T_{1}, T_{3}$, $T_{2}$, and $T_{4}$ are the lead and lag time constants of two phase compensation links, respectively.

If the PSS is added to IEEE9 system generator 2, the voltage equation needs to be

$$
\left\{\begin{array}{l}
\Delta u_{\mathrm{d} 2}=\Delta e_{\mathrm{d}}^{\prime}-R_{\mathrm{a} 2} \Delta i_{\mathrm{d} 2}+X_{\mathrm{q} 2}^{\prime} \Delta i_{\mathrm{q} 2}, \\
\Delta u_{\mathrm{q} 2}=\Delta e_{\mathrm{q}}^{\prime}-R_{\mathrm{a} 2} \Delta i_{\mathrm{q} 2}+X_{\mathrm{d} 2}^{\prime} \Delta i_{\mathrm{d} 2}+\Delta V_{\mathrm{S}} .
\end{array}\right.
$$

4.2. PSS Grid-Connected Position Selection. When OWFs integrate into load node 6 and in normal operation, the changes of the electromechanical oscillation mode are shown in Table 2.

As can be seen from Table 2, in the eigenvectors of the first and fourth modes, the modulus value of $\Delta s$ is the largest, but the directions of each component are basically the same, indicating that the influence of each generator on the mode is similar. In the second mode, the modulus value of $\Delta \omega_{3}$ and $\Delta s$ is larger and opposite to the direction of other components (the average argument is about $-154.57^{\circ}$ ), indicating that the oscillation mainly exists in generators 3,10 and generators 1,2 . The oscillation frequency $f=8.65 /(2 \pi)=$ $1.3767 \mathrm{~Hz}$, belonging to the local oscillation mode. In the 


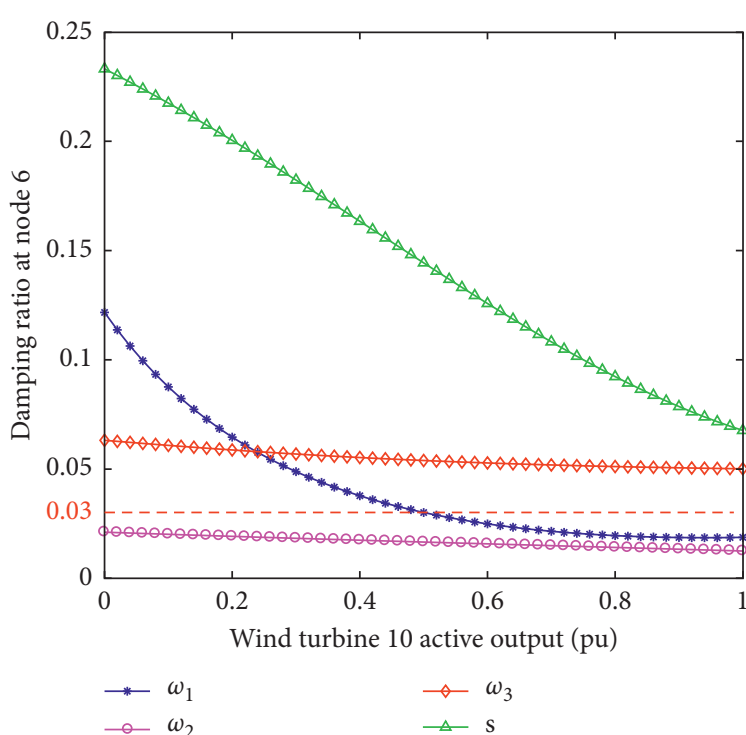

(a)

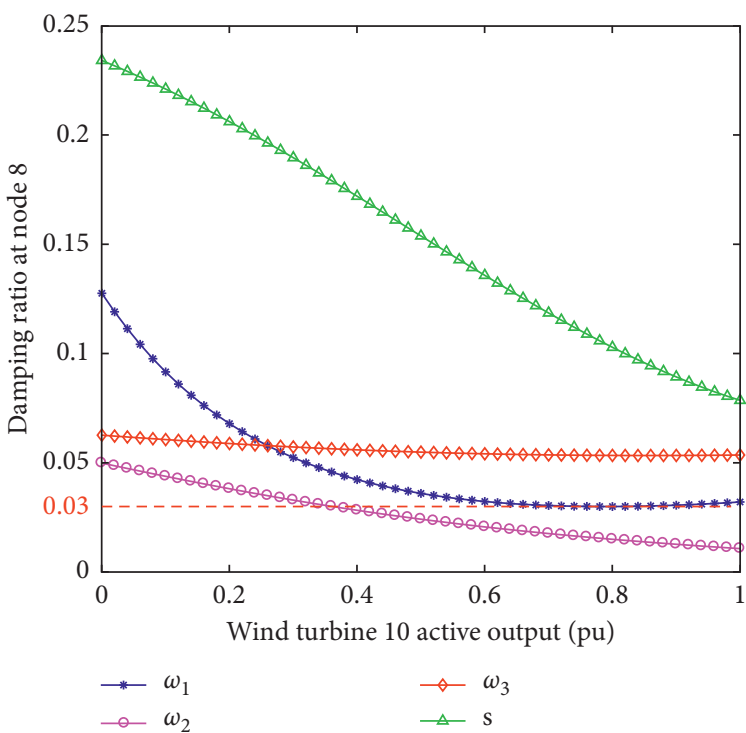

(c)

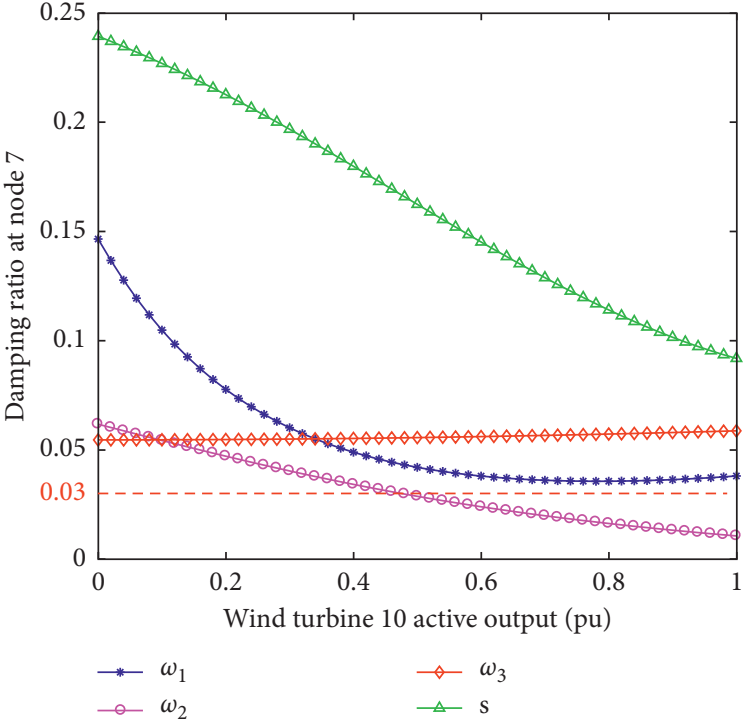

(b)

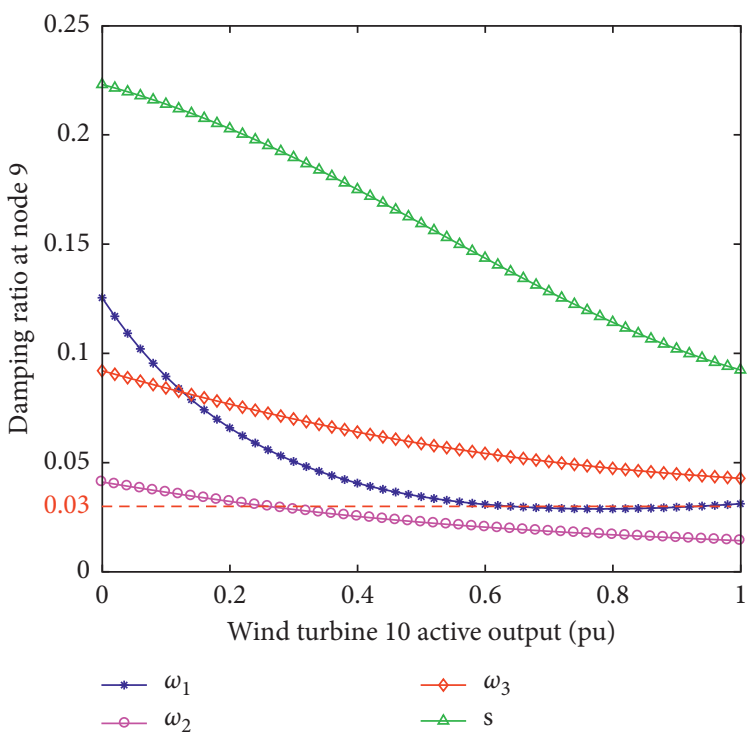

(d)

FIgURE 5: The damping ratio of OWF grid connection.

TABLE 2: Corresponding components of generator speed in the right eigenvector.

\begin{tabular}{|c|c|c|c|c|c|c|c|c|}
\hline \multirow[b]{2}{*}{ Generator } & \multicolumn{2}{|c|}{$\lambda_{7,8}$} & \multicolumn{2}{|c|}{$\lambda_{10,11}$} & \multicolumn{2}{|c|}{$\lambda_{12,13}$} & \multicolumn{2}{|c|}{$\lambda_{16,17}$} \\
\hline & $\begin{array}{l}\text { Modulus value } \\
(\mathrm{pu})\end{array}$ & $\begin{array}{c}\text { Argument } \\
\left({ }^{\circ}\right)\end{array}$ & $\begin{array}{l}\text { Modulus value } \\
(\mathrm{pu})\end{array}$ & $\begin{array}{c}\text { Argument } \\
\left({ }^{\circ}\right)\end{array}$ & $\begin{array}{l}\text { Modulus value } \\
(\mathrm{pu})\end{array}$ & $\begin{array}{c}\text { Argument } \\
\left({ }^{\circ}\right)\end{array}$ & $\begin{array}{l}\text { Modulus value } \\
\text { (pu) }\end{array}$ & $\underset{\left({ }^{\circ}\right)}{\text { Argument }}$ \\
\hline 1 & 0.0000 & -65.65 & 0.0002 & -158.19 & 0.0009 & -108.95 & 0.0007 & -73.93 \\
\hline 2 & 0.0001 & -50.39 & 0.0012 & -150.94 & 0.0024 & 69.35 & 0.0006 & -81.42 \\
\hline 3 & 0.0003 & -57.68 & 0.0040 & 26.21 & 0.0013 & 72.60 & 0.0005 & -81.49 \\
\hline 10 & 0.0115 & -42.98 & 0.0046 & 23.87 & 0.0025 & 72.36 & 0.0021 & -78.95 \\
\hline
\end{tabular}

third mode, the modulus values of $\Delta \omega_{2}$ and $\Delta s$ are larger and are basically opposite to $\Delta \omega_{1}$ in the direction (the argument is $-108.95^{\circ}$ ), indicating that the oscillation mainly exists in generators 2, 10 and generator 1 . The oscillation frequency $f=12.89 /(2 \pi)=2.0515 \mathrm{~Hz}$, belonging to the local oscillation mode.

In the participation vector, if the generator speed component is positive and the value is large, it indicates that 
the generator is the best candidate position for installing the PSS, which can significantly increase the damping of the mode. For increasing system damping, it is better to apply control on a larger capacity generator [30].

The local oscillation modes $\lambda_{10,11}$ and $\lambda_{12,13}$ are specifically analyzed. The components of the participation vector corresponding to the rotation speed of each generator are shown in Table 3.

As can be seen from Table 3, for the participation vector of local mode $\lambda_{10,11}$, the value of generator 3 is the largest and that of generator 10 is the smallest, indicating that the control is mainly applied in generator 3 , and the damping of the system can be significantly increased. Similarly, for the participation vector of local mode $\lambda_{12,13}$, the value of generator 2 is the largest and that of generator 10 is the smallest, indicating that fine effects can be achieved by applying control on generator 2 .

Furthermore, compared with the capacity of generators 2 and 3 , the active power of generator $2(1.63 \mathrm{pu})$ is larger than that of generator $3(0.85 \mathrm{pu})$, so the damping control of generator 2 can achieve better suppression of the oscillation effect.

4.3. PSO Algorithm Based on Different Inertia Weight Functions. The updating formulas of particle velocity and position are as follows:

$$
\begin{aligned}
v_{i D}^{k+1} & =\omega v_{i D}^{k}+c_{1} r_{1}\left(p_{i D}^{k}-x_{i D}^{k}\right)+c_{2} r_{2}\left(p_{g D}^{k}-x_{g D}^{k}\right), \\
x_{i D}^{k+1} & =x_{i D}^{k}+v_{i D}^{k+1},
\end{aligned}
$$

where $k$ represents the number of iterations; $v_{i D}^{k}$ and $x_{i D}^{k}$ represent the velocity and position of the $i$-th particle in the $D$-dimensional space, and the value range is $\left[\nu_{\mathrm{lb}}, \nu_{\mathrm{ub}}\right]$ and $\left[x_{\mathrm{lb}}, x_{\mathrm{ub}}\right]$; and $c_{1}$ and $c_{2}$ refer to the individual learning factors and the group learning factors, and $c_{1}=c_{2}=2$ is taken in this paper. $r_{1}$ and $r_{2}$ are random numbers between 0 and $1 ; p_{i D}^{k}$ and $p_{g D}^{k}$ represent the individual optimal position and the global optimal position of the $i$-th and $g$-th particle in the $D$-dimensional space; and $\omega$ represents the inertia weight.

The inertia weight $\omega$ indicates the ability to retain existing velocity. The larger the value is, the stronger the global optimization is. On the contrary, the smaller the value is, the better the local optimization is. In order to weigh the global optimization and local optimization, Shi. Y summarized a new method of calculating weights, linear decreasing inertia weights (LDIW) [31], which is specifically expressed as

$$
\omega 1(k)=\omega_{\text {start }}-\left(\omega_{\text {start }}-\omega_{\text {end }}\right) \frac{k}{T_{\text {max }}},
$$

where $\omega_{\text {start }}$ is the inertia weight in the initial state; $\omega_{\text {end }}$ is the inertia weight at the end of the iteration; $k$ is the number of iterations; and $T_{\max }$ is the maximum number of iterations. It is generally believed that $\omega_{\text {start }}=0.9$ and $\omega_{\text {end }}=0.4$ in which the algorithm performs best. In addition to LDIW, the common inertia weight functions [32] are as follows:
TABLE 3: Components of the participation vector corresponding to the rotation speed of each generator.

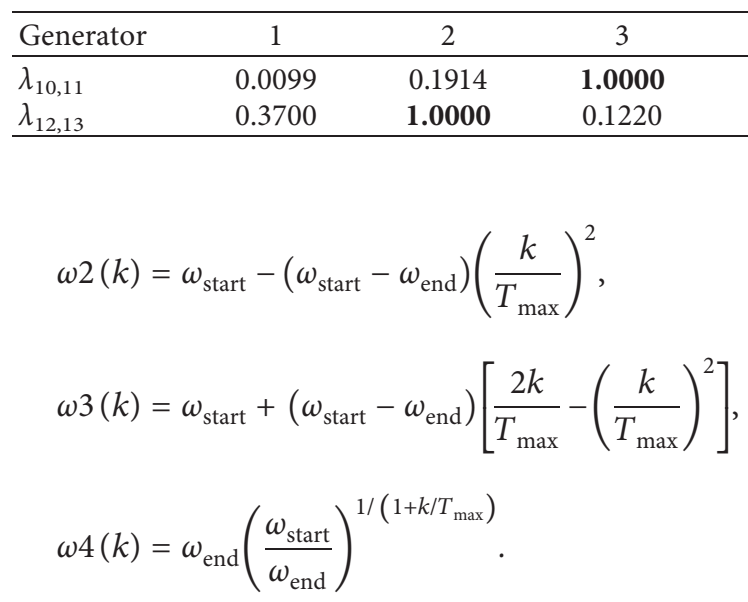

4.4. Determination of Optimization Objective Function. In order to improve the weak damping of the system, it is very important to determine the optimal target. As can be seen from Figure 5, when OWFs first join the system, the damping ratio is relatively large. With the increase of the active power output, most damping ratios show a downward trend, and some electromechanical oscillation modes even have weakly damped unstable states. In order to improve the low-frequency oscillation, when generator 10 active output is $1.0 \mathrm{pu}$, the minimum damping ratio of each generator is selected as the optimal target, and then the maximum value of this target in the iterative process can be obtained by the PSO algorithm. If the optimization target is larger than 0.03 , the variation curve of damping ratio can be ensured to be in a stable running state. The mathematical expressions of fitness function are as follows:

$$
\begin{aligned}
D_{n} & =\min \left(\zeta_{n i}\right), \\
\text { fitness } & =\max \left(D_{n}\right),
\end{aligned}
$$

where $\xi_{n i}(i=1,2,3,4)$ is the damping ratio of the component related to the rotation speed of generators $1,2,3$, and 10 during the $n$-th iteration process.

According to the research of this topic, the steps of the PSO algorithm are as follows:

(1) Initialize particle swarm size, velocity, and position. Particle specifically refers to PSS parameters.

(2) Take the small-signal stability program as a subfunction, and then optimize the designed objective function to obtain the individual and the global optimal fitness value of the particle.

(3) Compare the fitness value of each generation particle. If the current fitness value is better, update the previously recorded optimal fitness value with the current fitness value, and update the previously recorded optimal position with the current position. If not, leave the value unchanged. 


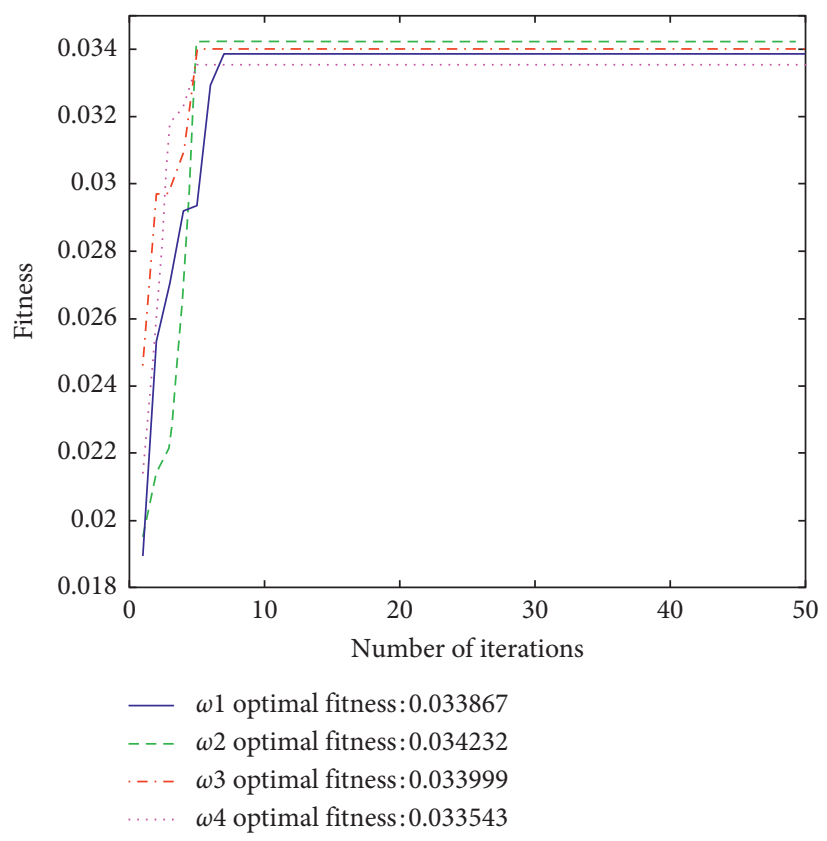

Figure 6: Fitness curves under different inertia weights.
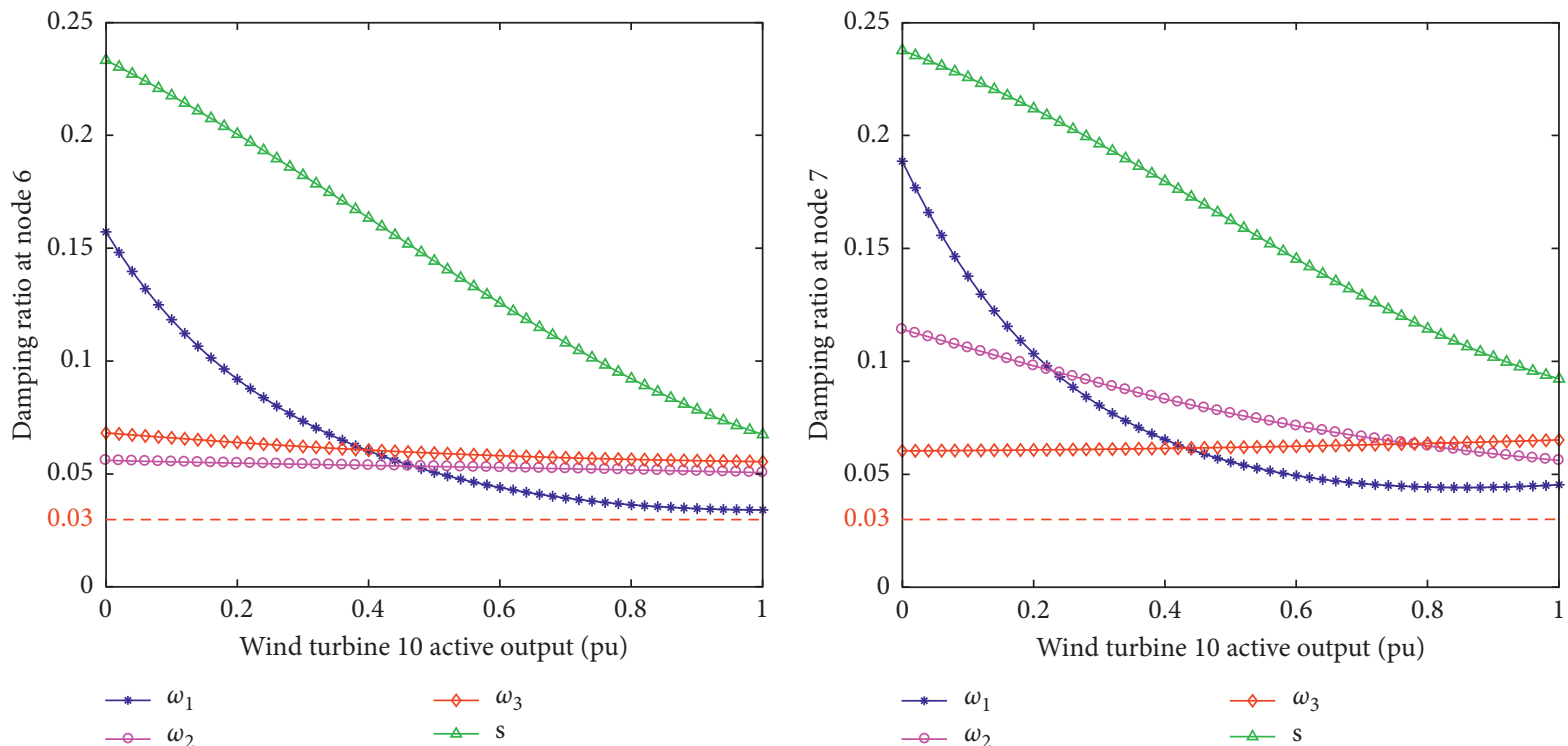

(a)

Figure 7: Continued.

(b) 


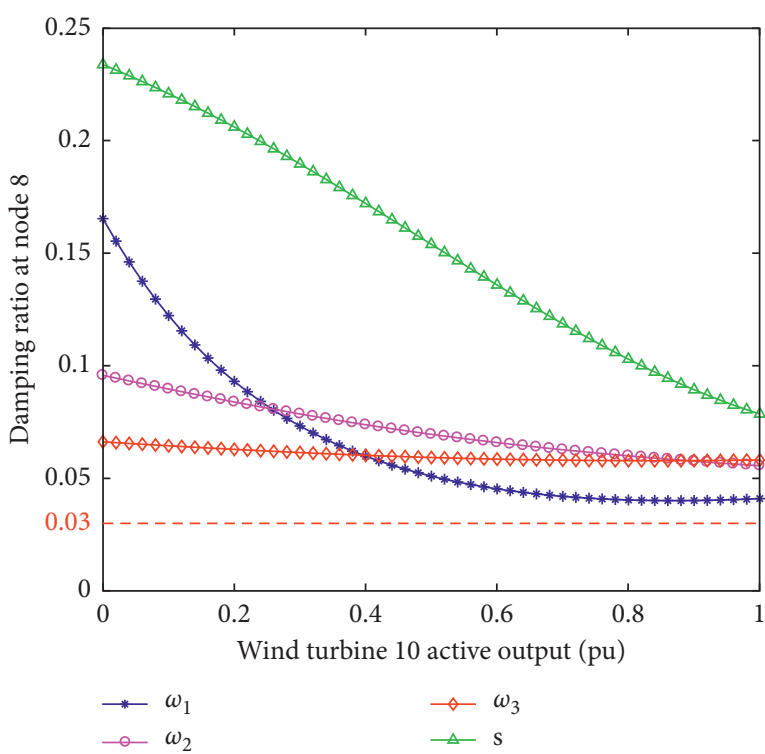

(c)

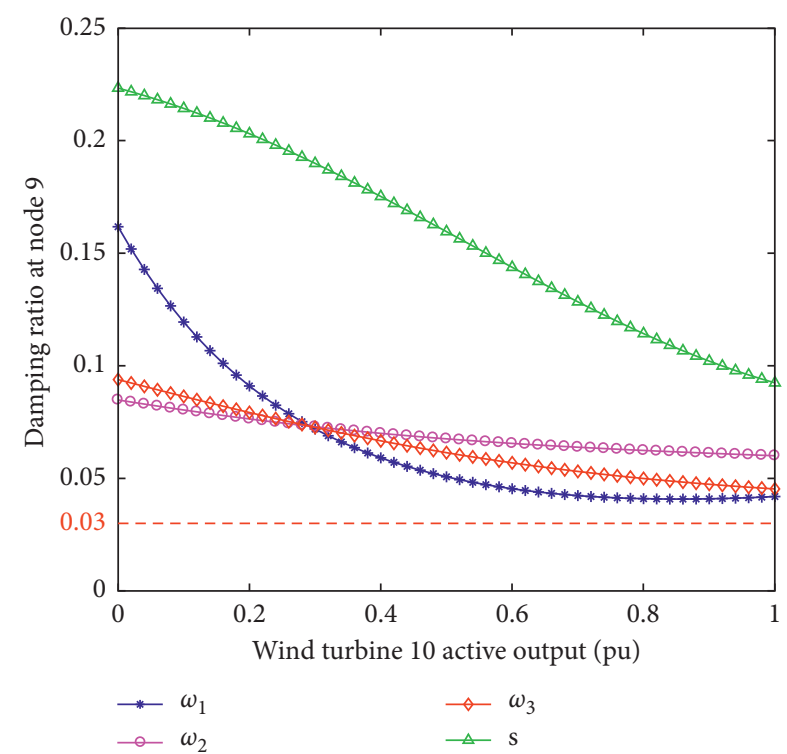

(d)

FIGURE 7: Curve of damping ratio change after the PSS is added into generator 2.

(4) Update the position and velocity of each particle.

(5) Determine whether the current fitness value reaches the given standard or reaches the upper limit of the number of iterations. If yes, the program ends. If not, return to (2) and continue to execute the loop body.

4.5. Effect of Applying PSS Control. According to the analysis of Section 4.3, PSS installed in generator 2 works well. Under different inertial weights, the fitness curve can be obtained by solving the function for many times and taking the mean value, as shown in Figure 6.

It can be seen from Figure 6 that the deviation of the optimal fitness obtained under the four inertia weights is small. The optimal fitness of the inertia weight $\omega 2$ is 0.034232 , the effect of $\omega 1$ and $\omega 3$ is similar, and the worst is $\omega 4$. Based on $\omega 2$, the control parameters are deeply optimized, and the optimized parameters of each controller are $K_{\text {gain }}=10, T_{1}=0.66, T_{2}=0.25, T_{3}=0.45, T_{4}=0.15, T_{5}=4.5$, and $T_{6}=1.25$. By substituting the PSS parameters into the original state matrix and changing the position and capacity of the offshore wind power into the power system, the effect can be obtained, as shown in Figure 7.

As can be seen from Figure 7, after adding the PSS to generator 2, each damping ratio is improved correspondingly, and the curves are all above 0.03 , indicating that the system works stably. The variation trend of each damping ratio is basically the same as that without the PSS, and the damping ratio of generator 2 rotation speed is significantly increased. Furthermore, it can be verified that the theoretical analysis is reasonable, and generator 2 is the best place to add the PSS.

\section{Simulink Simulation}

Through theoretical analysis and programming experiments, the control measures of offshore wind power grid connection have been obtained. However, how the actual power system operates and whether the controller PSS achieves the desired effect need to be verified by simulation. The circuit in Figure 1 was built on MATLAB/Simulink. By applying the small signal (wind speed disturbance and system fault), the proposed control measures are verified and analyzed.

5.1. Wind Speed Disturbance. Assuming the initial wind speed of the OWFs is $10 \mathrm{~m} / \mathrm{s}$, a step signal generator disturbs the wind speed to $12 \mathrm{~m} / \mathrm{s}$ at $1.8 \mathrm{~s}$. The dynamic response effect of the system before and after adding PSS control to generator 2 is shown in Figure 8.

From the PSS2 control in Figures 8(a) and 8(c), it can be clearly seen that the power of the system fluctuates within a small range after applying the wind speed disturbance, and the system runs stably again at $3.3 \mathrm{~s}$. The process has gone through $1.5 \mathrm{~s}$; it can be seen from Figure 8(a) that, after the addition of PSS2, the electromagnetic torque of synchronous generator 1 is stabilized more quickly, and the oscillation amplitude is effectively suppressed. Figure 8(b) is the voltage curve of synchronous generator 1 , and the effect of adding PSS2 is small. It can be seen from Figure 8(c) that the amplitude of the synchronous generator 1 active power is significantly reduced after the addition of PSS2. Figure 8(d) shows the DC curve of HVDC. By comparison, the amplitude of the oscillation is reduced when PSS2 is applied. The amplitude of the voltage stability will drop slightly without PSS2 control, which is also the adverse effect of wind speed disturbance. Figures $8(\mathrm{e})$ and $8(\mathrm{f})$ show the active and reactive power of VSC1. It can be seen that, after the addition of the damping controller, the oscillation of the system is better improved. In summary, when the OWFs are disturbed by wind speed, adding PSS2 will improve the small-signal stability of the whole system. 


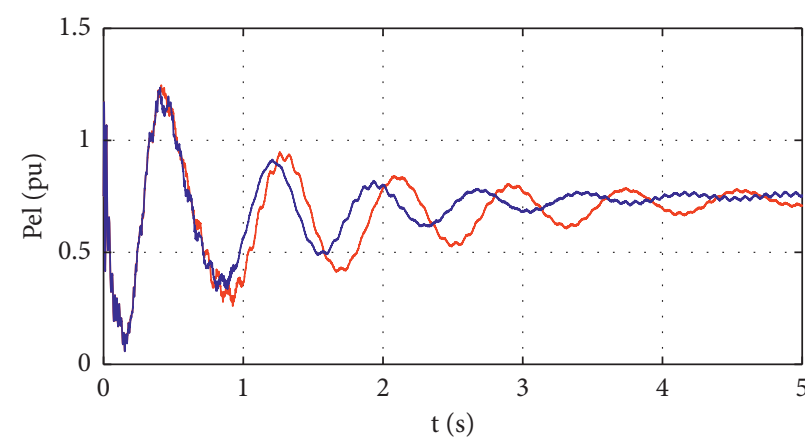

— Without PSS2 control

- With PSS2 control

(a)

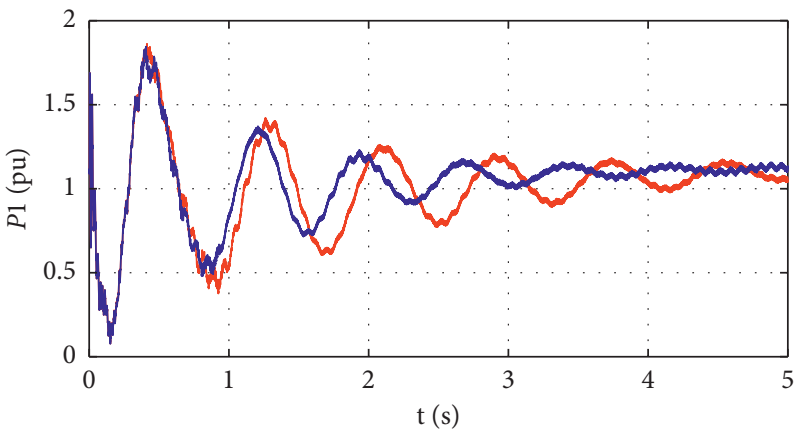

— Without PSS2 control

With PSS2 control

(c)

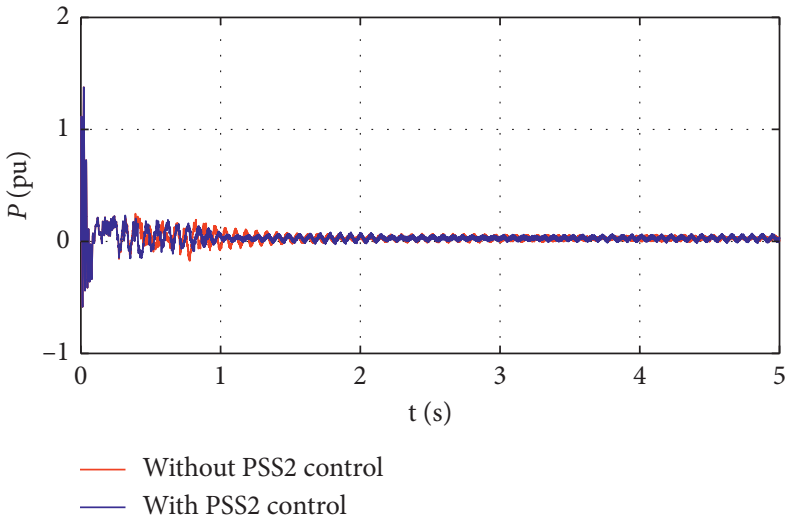

(e)

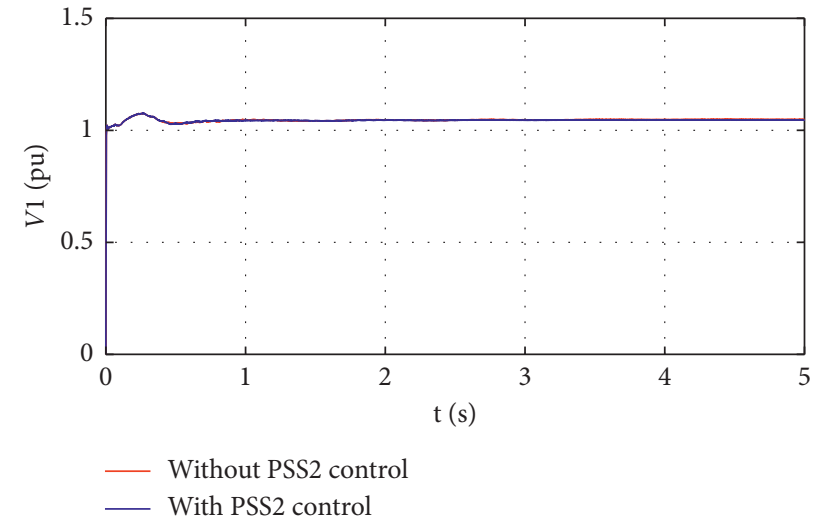

(b)

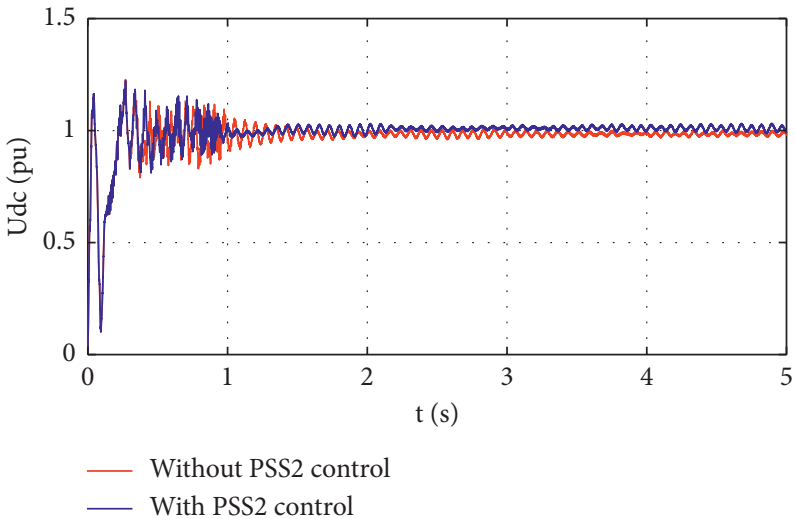

(d)

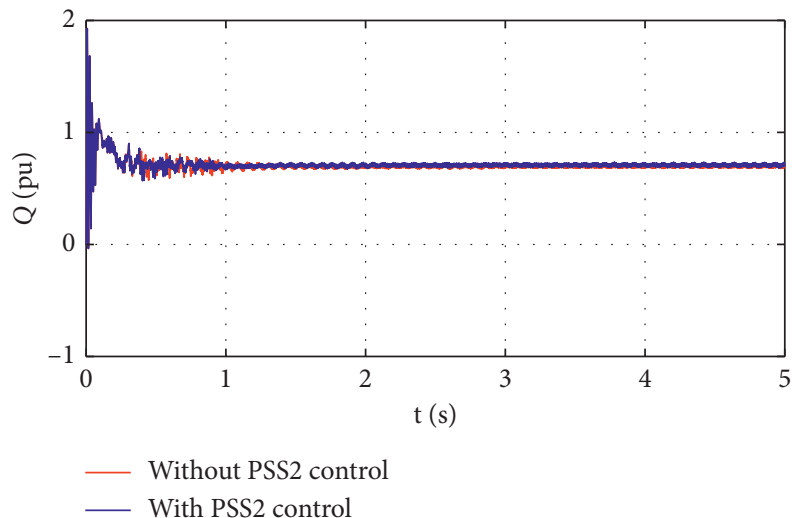

(f)

FIGURE 8: Dynamic response of the system before and after adding PSS2 in the case of wind speed disturbance. (a) The electromagnetic torque of synchronous generator 1. (b) The voltage of synchronous generator 1. (c) The active power of synchronous generator 1. (d) The direct current voltage of HVDC. (e) The active power of VSC1. (f) The reactive power of VSC1.

5.2. System Fault. In order to simulate the actual system fault, a three-phase short circuit was applied to the transmission line incorporated into node 8 at $1.5 \mathrm{~s}$, and the fault duration is $0.12 \mathrm{~s}$. The dynamic response of the system controlled by PSS2 is shown in Figure 9.

It can be seen from Figures $9(\mathrm{a})$ and 9(f) that, after applying a three-phase short-circuit fault, the state of the system changes obviously. The system recovers at $2.8 \mathrm{~s}$, and the adjustment process goes through $1.3 \mathrm{~s}$; Figure 9(a) is the electromagnetic torque curve of synchronous generator 1 , and the oscillation of the system is significantly reduced after the addition of PSS2. Figure 9(b) shows the voltage curve of synchronous generator 1 , and the effect of adding or not adding PSS2 is small. It can be seen from Figure 9(c) that the amplitude of the synchronous generator 1 active power is remarkably suppressed after the addition of PSS2. 


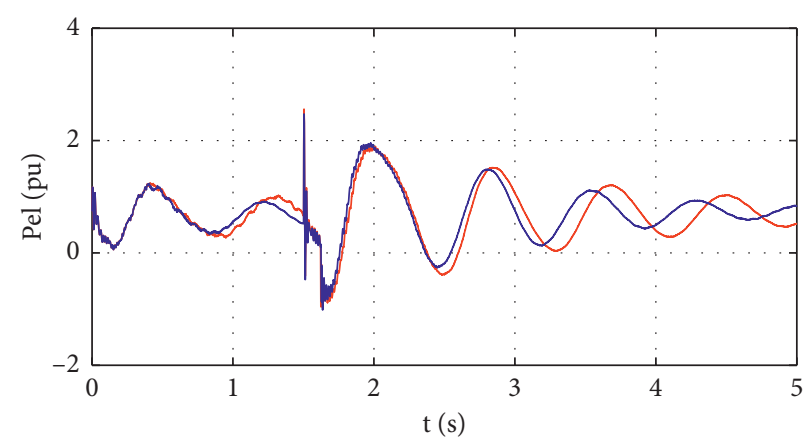

Without PSS2 control

With PSS2 control

(a)

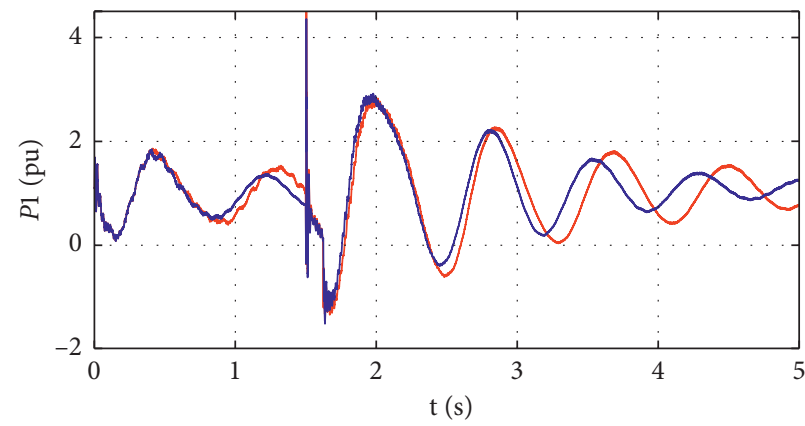

Without PSS2 control

— With PSS2 control

(c)

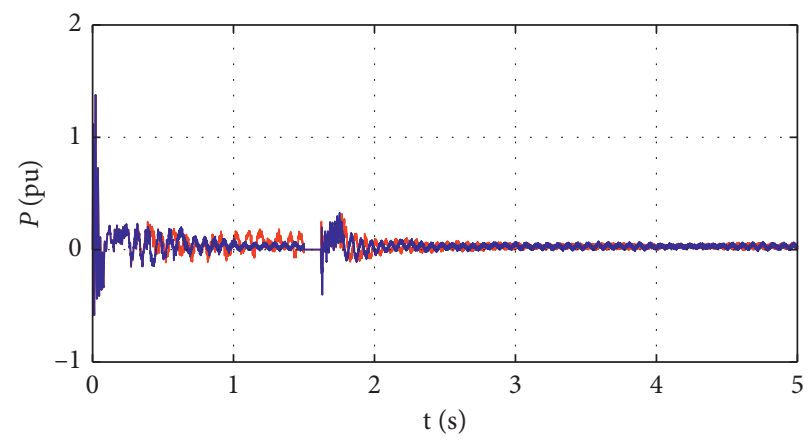

Without PSS2 control With PSS2 control

(e)

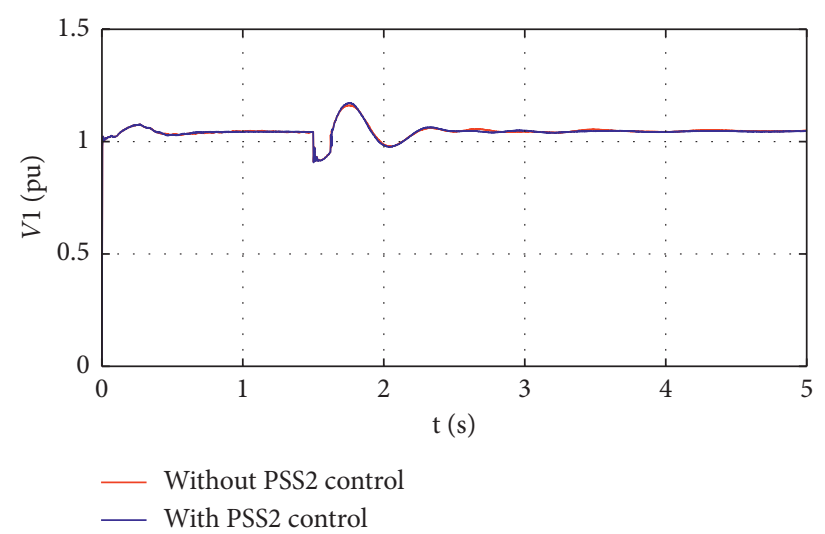

(b)

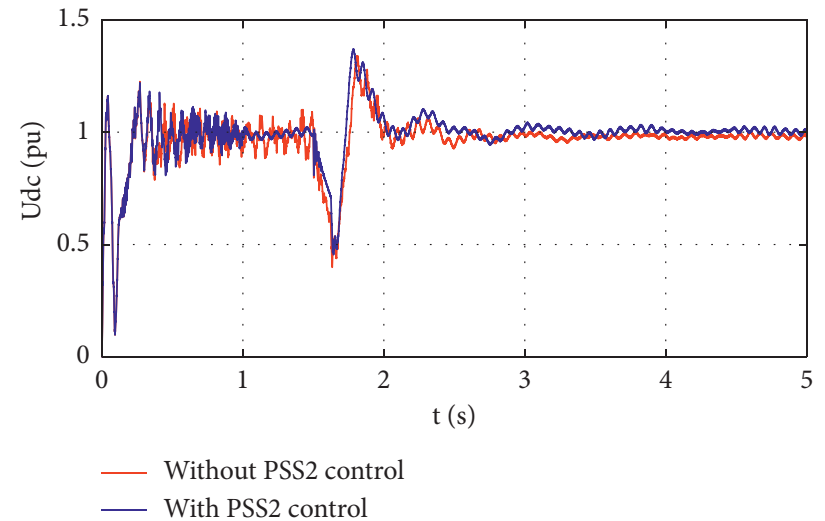

(d)

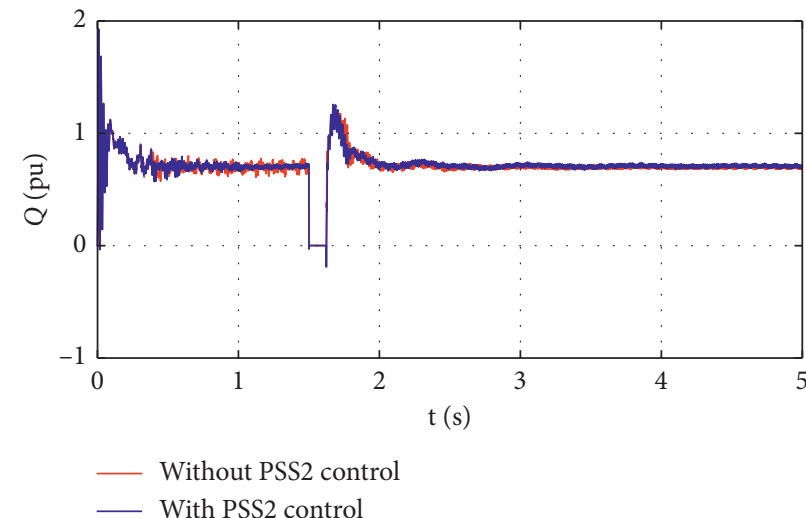

(f)

FIGURe 9: Dynamic response of the system before and after adding PSS2 in the case of the three-phase short-circuit fault. (a) The electromagnetic torque of synchronous generator 1. (b) The voltage of synchronous generator 1. (c) The active power of synchronous generator 1. (d) The direct current voltage of HVDC. (e) The active power of VSC1. (f) The reactive power of VSC1.

Figure 9(d)shows the DC curve of HVDC. It can be seen that the DC voltage fluctuation amplitude is reduced, and the system reaches stability more quickly. Figures $9(\mathrm{e})$ and 9 (f) show the active and reactive power of VSC1. It can be seen that, after the damping controller is added, the oscillation of the system is better improved. In summary, when the onshore power system is disturbed by the fault, adding PSS2 improves the small-signal stability of the whole system.

\section{Conclusions}

Based on the establishment of a complete mathematical model, the influence of offshore wind power on the system at different positions and capacities is analyzed in detail according to the damping characteristics. The experimental results show that most of the damping ratios are decreasing, and some of the electromechanical oscillation modes will show weak damping instability. By comparing the 
experimental results of two load nodes and two generator nodes, the optimal location and capacity of offshore wind farms are obtained. In order to improve the weak damping of the power system, the optimal positions of the PSS in the power grid are obtained through the modal control. PSO algorithm combining with different inertia weight functions is presented to determine the parameters of the PSS. Finally, the whole system model is built on MATLAB/ Simulink platform, and the influence of PSS control on the system is compared and analyzed by applying wind speed disturbance and system fault. The simulation results show that the dynamic response of the system is obviously improved, the oscillation amplitude is significantly reduced, and the accuracy of the proposed control strategy is verified.

\section{Appendix}

DFIG parameters of offshore wind farms:

$$
\begin{aligned}
& r=40 \mathrm{~m} ; \quad \rho=1.242 \mathrm{~kg} \mathrm{~m}^{3} ; \quad v_{0}=10.45 \mathrm{~m} \mathrm{~s}^{-1} \quad R_{\mathrm{r}}= \\
& 0.0073 \mathrm{pu} ; R_{\mathrm{s}}=0.0076 \mathrm{pu} ; L_{\mathrm{r}}=0.0884 \mathrm{pu} ; L_{\mathrm{s}}=0.1248 \mathrm{pu} ; \\
& L_{\mathrm{m}}=1.8365 \mathrm{pu} ; \quad \omega_{\mathrm{t} 0}=1.1055 \mathrm{rad} \mathrm{s}^{-1} ; \quad s_{0}=-0.003 ; \\
& \beta_{0}=0 \mathrm{rad} ; K_{\mathrm{p} 0}=0.1 \mathrm{pu} ; K_{\mathrm{I} 0}=20 \mathrm{~s}^{-1} ; T_{\beta}=10 \mathrm{~s} ; H_{\mathrm{t}}=3 \mathrm{~s} ; \\
& H_{\mathrm{g}}=0.05 \mathrm{~s} ; K=10 \mathrm{pu}^{-1} ; \text { and } D=0.5 \mathrm{pu}^{-1} \mathrm{rad}^{-1} . \\
& \text { VSC-HVDC parameters: } \\
& R_{1}=R_{2}=0.075 \mathrm{pu} ; \quad L_{1}=L_{2}=0.016 \mathrm{pu} ; \quad \omega_{1}=\omega_{2}=1 \mathrm{pu} ; \\
& \boldsymbol{\delta}_{1}=\boldsymbol{\delta}_{2}=10^{\circ} ; \quad K_{1}=K_{2}=0.1 ; \quad R_{\mathrm{d}}=1.0425 \mathrm{pu} ; \\
& L_{\mathrm{d}}=0.0119 \mathrm{pu} ; \text { and } C=0.1733 \mathrm{pu} .
\end{aligned}
$$

System interface parameters:

$$
\begin{aligned}
& X_{\mathrm{T} 0}=0.015 \mathrm{pu} ; \quad X_{\mathrm{T} 1}=0.016 \mathrm{pu} ; \quad X_{\mathrm{L} 1}=0.02 \mathrm{pu} ; \\
& X_{\mathrm{T} 2}=0.061 \mathrm{pu} ; \text { and } X_{\mathrm{L} 2}=0.014 \mathrm{pu} .
\end{aligned}
$$

\section{Data Availability}

All data generated or analyzed during this study are included in this article.

\section{Conflicts of Interest}

The authors declare no conflicts of interest.

\section{Acknowledgments}

This paper was carefully guided by Professor Ru Yang of Guangzhou University and was supported by the National Natural Science Foundation of China under Grant nos. 61772147 and 61100150, the University Innovation Team Construction Project of Guangdong Province under Grant no. 2015KCXTD014, Guangdong Province Philosophy and Social Science Foundation under Grant no. GD19CSH03, the key Project of Science and Technology Plan of Guangdong Province under Grant No. 2020b1010010014 and Open Research Fund Program of Data Recovery Key Laboratory of Sichuan Province. Here, the authors express their sincere gratitude.

\section{References}

[1] I. Pineda, K. Ruby, A. Ho, A. Mbistrova, and G. Corbetta, "The European Offshore Wind Industry-Key Trends and Statistics 2015, European Wind Energy Association, Brussels, Belgium, 2016.

[2] C. Walsh, L. Miró, F. Selot, D. Fraile, and G. Brindley, "Offshore Wind in Europe - Key Trends and Statistics 2018, Wind Europe, Brussels, Belgium, 2019.

[3] P. Tardieu, L. Velde, A. Nghiem, and I. Pineda, Wind Energy in Europe: Scenarios for 2030, Wind Europe, Brussels, Belgium, 2017.

[4] L. Shen, M. Barnes, R. Preece, and J. Milanović, "Frequency stabilisation using VSC-HVDC," in Proceedings of the 2016 IEEE Power and Energy Society General Meeting (PESGM), pp. 1-5, Boston, MA, USA, 2016.

[5] L. Yan, S. Wei, C. Yong-Ning, W. Lin-Jun, and L. Wei, "Research on offshore wind farm VSC-HVDC transmission system fault ride through issue," in Proceedings of the 2014 International Conference on Power System Technology, pp. 2190-2195, Chengdu, China, 2014.

[6] K. Asimenia, Q. Wu, and H. Zhao, "Review of VSC HVDC connection for offshore wind power integration," Renewable and Sustainable Energy Reviews, vol. 59, pp. 1405-1414, 2016.

[7] M. Edrah, K. L. Lo, O. Anaya-Lara, and A. Elansari, "Impact of DFIG based offshore wind farms connected through VSCHVDC link on power system stability," in Proceedings of the 11th IET International Conference on AC and DC Power Transmission, pp. 1-7, Birmingham, UK, 2015.

[8] Q. Fu, W. Du, J. Cao, and H. F. Wang, "“VSC-based HVDC power transmission for the large-scale offshore wind power-a survey," in Proceedings of the International Conference on Renewable Power Generation (RPG 2015), pp. 1-6, Beijing, China, 2015.

[9] S. Lu and Z. Xu, "A novel control strategy of VSC-HVDC for offshore platforms," in Proceedings of the 12th IET International Conference on AC and DC Power Transmission (ACDC 2016), pp. 1-6, Beijing China, 2016.

[10] Y. Guo, H. Gao, Q. Wu, H. Zhao, J. Ostergaard, and M. Shahidehpour, "Enhanced voltage control of VSC-HVDCConnected offshore wind farms based on model predictive control," IEEE Transactions on Sustainable Energy, vol. 9, no. 1, pp. 474-487, 2018.

[11] J. Machowski, J. Bialek, and J. Bumby, Power System Dynamics: Stability and Control, Wiley, New York, NY, USA, 2nd edition, 2008.

[12] H. Huang, C. Mao, J. Lu, and D. Wang, "Small-signal modelling and analysis of wind turbine with direct drive permanent magnet synchronous generator connected to power grid," IET Renewable Power Generation, vol. 6, no. 1, pp. 48-58, 2012.

[13] Y. Yang and G. Li, "The small signal stability control of offshore wind farm based on VSC-HVDC," Transactions of China Elect Rotechnical Society, vol. 31, no. 13, pp. 101-110, 2016.

[14] A. Sajadi, S. Zhao, K. Clark, and K. A. Loparo, "Small-signal stability analysis of large-scale power systems in response to variability of offshore wind power plants," IEEE Systems Journal, vol. 13, no. 3, pp. 1-10, 2018.

[15] M. Raza, E. Prieto-Araujo, and O. Gomis-Bellmunt, "Smallsignal stability analysis of offshore AC network having multiple VSC-HVDC systems," IEEE Transactions on Power Delivery, vol. 33, no. 2, pp. 830-839, 2018.

[16] C. Wang, H. Fang, and S. He, "Adaptive optimal controller design for a class of LDI-based neural network systems with 
input time-delays," Neurocomputing, vol. 385, pp. 292-299, 2020.

[17] S. He, H. Fang, M. Zhang, F. Liu, and Z. Ding, "Adaptive optimal control for a class of nonlinear systems: the online policy iteration approach," IEEE Transactions on Neural Networks and Learning Systems, vol. 31, no. 2, pp. 549-558, 2020.

[18] S. He, H. Fang, M. Zhang, F. Liu, X. Luan, and Z. Ding, "Online policy iterative-based Ho optimization algorithm for a class of nonlinear systems," Information Sciences, vol. 495, pp. 1-13, 2019.

[19] S. He, M. Zhang, H. Fang, F. Liu, X. Luan, and Z. Ding, "Reinforcement learning and adaptive optimization of a class of Markov jump systems with completely unknown dynamic information," Neural Computing and Applications, 2019.

[20] F. Wu, X.-P. Zhang, K. Godfrey, and P. Ju, "Small signal stability analysis and optimal control of a wind turbine with doubly fed induction generator," IET Generation, Transmission \& Distribution, vol. 1, no. 5, pp. 751-760, 2007.

[21] G. Tang, HVDC Transmission Technology Based on Voltage Source Converter, China Electric Power Press, Beijing, China, 2010.

[22] C. Qin and Y. Yu, "Small signal stability region of power systems with DFIG in injection space," Journal of Modern Power Systems and Clean Energy, vol. 1, no. 2, pp. 127-133, 2013.

[23] Z. Li, X. Zhang, Y. Deng, and B. He, "Studies of transient stability of wind power acess grid system," J of China Three Gorges Univ. (Natural Sciences), vol. 38, no. 2, pp. 47-50, 2016.

[24] B. Mehta, P. Bhatt, and V. Pandya, "Small signal stability analysis of power systems with DFIG based wind power penetration," International Journal of Electrical Power \& Energy Systems, vol. 58, pp. 64-74, 2018.

[25] E. Prasanthi and K. N. Shubhanga, "Stability analysis of a grid connected DFIG based WECS with two-mass shaft modeling," in Proceedings of the 2016 IEEE Annual India Conference (INDICON), pp. 1-6, Bangalore, India, 2016.

[26] S. Feng, D. Liu, X. Yang, and X. Xiang, "The impact of wind power inverse-peaking characteristics on power system low frequency oscillation," in Proceedings of the 2012 China International Conference on Electricity Distribution, pp. 1-4, Shanghai, China, 2012.

[27] H. Huang, Research on Small-Signal Stability of Wind and Photovoltaic Power Generation System, Ph.D. dissertation, Department Electronical Engineering, HUST University, Wuhan, China, 2012.

[28] X. Wang, W. Fang, and Z. Du, Modern Power System Analysis, Science Press, Beijing, China, 2003.

[29] K. Thanpisit and I. Ngamroo, "Power oscillation damping control by PSS and DFIG wind turbine under multiple operating conditions," Turkish Journal of Electrical Engineering \& Computer Sciences, vol. 25, pp. 4354-4368, 2017.

[30] D. Gautam and V. Vittal, "Impact of DFIG based wind turbine generators on transient and small signal stability of power systems,", in Proceedings of the 2009 IEEE Power \& Energy Society General Meeting, pp. 1-6, Calgary, Canada, 2009.

[31] J. Xin, G. Chen, and Y. Hai, "A particle swarm optimizer with multi-stage linearly-decreasing inertia weight,", in Proceedings of the 2009 International Joint Conference on Computational Sciences and Optimization, pp. 505-508, Sanya, China, 2009.

[32] L. Yu, F. Shi, H. Wang, and F. Hu, Analysis of 30 Cases of Intelligent Algorithms in MATLAB, Beihang University Press, Beijing, China, 2011. 